\title{
Yes, but does medical education produce better doctors?
}

Citation for published version (APA):

Schuwirth, L., \& van der Vleuten, C. (2019). Yes, but does medical education produce better doctors? Education for Primary Care, 30(6), 333-336. https://doi.org/10.1080/14739879.2019.1670098

Document status and date:

Published: 01/01/2019

DOI:

10.1080/14739879.2019.1670098

Document Version:

Publisher's PDF, also known as Version of record

Document license:

Taverne

Please check the document version of this publication:

- A submitted manuscript is the version of the article upon submission and before peer-review. There can be important differences between the submitted version and the official published version of record.

People interested in the research are advised to contact the author for the final version of the publication, or visit the DOI to the publisher's website.

- The final author version and the galley proof are versions of the publication after peer review.

- The final published version features the final layout of the paper including the volume, issue and page numbers.

Link to publication

\footnotetext{
General rights rights.

- You may freely distribute the URL identifying the publication in the public portal. please follow below link for the End User Agreement:

www.umlib.nl/taverne-license

Take down policy

If you believe that this document breaches copyright please contact us at:

repository@maastrichtuniversity.nl

providing details and we will investigate your claim.
}

Copyright and moral rights for the publications made accessible in the public portal are retained by the authors and/or other copyright owners and it is a condition of accessing publications that users recognise and abide by the legal requirements associated with these

- Users may download and print one copy of any publication from the public portal for the purpose of private study or research.

- You may not further distribute the material or use it for any profit-making activity or commercial gain

If the publication is distributed under the terms of Article $25 \mathrm{fa}$ of the Dutch Copyright Act, indicated by the "Taverne" license above, 


\section{Education for Primary Care}

\section{Yes, but does medical education produce better doctors?}

\section{Lambert Schuwirth \& Cees van der Vleuten}

To cite this article: Lambert Schuwirth \& Cees van der Vleuten (2019) Yes, but does medical education produce better doctors?, Education for Primary Care, 30:6, 333-336, DOI: 10.1080/14739879.2019.1670098

To link to this article: https://doi.org/10.1080/14739879.2019.1670098

曲 Published online: 23 Sep 2019.

Submit your article to this journal $\asymp$

Џll Article views: 185

Q View related articles $\sqsubset$

View Crossmark data $\nearrow$ 


\title{
Yes, but does medical education produce better doctors?
}

\author{
Lambert Schuwirth (1D ${ }^{\mathrm{a}}$ and Cees van der Vleuten $\mathbb{1 D}^{\mathrm{b}}$ \\ aPrideaux Centre for Health Professions Education Research, Flinders University, Adelaide, Australia; ${ }^{b}$ Education Development and Research, \\ Maastricht University, Maastricht, Netherlands
}

ABSTRACT

Medical education research and development's reason for existence is their contribution to producing better doctors. Arguably this is as. notion that nobody would disagree with. But, answering this question is not as straightforward as it may look. In this paper we describe six complexities that impact on such research and unfortunately contribute to the difficulties surrounding medical education knowledge translation to practice.
ARTICLE HISTORY

Received 18 August 2019 Accepted 30 August 2019

KEYWORDS

Medical education; research; knowledge translation; complexity; competency based medical education

\section{Introduction}

Do all the innovations in medical education really produce better doctors? This is arguably the most central question to answer. Every research and development discipline seeks to improve the current situation and to do better tomorrow. So, when we talk about innovations in medical education we should actually be talking about improvements in medical education. This assumes that improvements in medical education will lead to better quality of doctors and better healthcare outcomes. Because, if they do not, then they would just be innovations for innovations' sake.

Although it is a straightforward question to ask, it is not an easy one to answer. It may be intuitively clear that a single study is never going to be enough. There can be no single causal comparative design, or randomised controlled trial, that can definitively show that one educational approach is inherently superior to another. When we think about programmes of research, there are a number of complexities that medical education research and development have to grapple with to address the question of whether it will contribute to educating better doctors. In this paper, we aim to briefly discuss what we see as the main complexities in designing medical education research.

\section{Complexity number 1: what is the definition of a good doctor?}

The notion of a 'good doctor' is a multifaceted, contextualised and time-bound concept. There is probably good agreement on this. What was a good doctor 50 years ago would not be seen as a good doctor currently. The doctor of 50 years ago might, for instance, have had more detailed anatomical knowledge, but perhaps lack the necessary negotiation and communication skills that modern healthcare requires. This is illustrated by the fact that 50 years ago a good doctor was defined as somebody who had the requisite knowledge, skills and problem-solving ability. Each of these was seen as a generic, independent and measurable 'personality trait'. Nowadays, all major bodies define the 'good doctor' in terms of competencies; abilities to apply knowledge, skills, professionalism and other metacognitive abilities in an integrated, holistic way to manage the challenges of professional practice.

Regulatory bodies such as the General Medical Council (GMC) UK, the Accreditation Council for Graduate Medical Education (ACGME) and the Royal College of Physicians and Surgeons in Canada (RCPSC) do not simply define a 'good doctor' as someone who has the-relevant knowledge and skills. They also place considerable emphasis on domainindependent abilities, such as communicator, collaborator, health advocate, scholar, professional and leader. A research study when seeking to compare outcomes of different educational approaches, might be relatively straightforward when comparing knowledge or technical skills. Whereas for domains such as health advocacy, professionalism and leadership, it rapidly becomes much more complex. This complexity is further increased by the fact that most clinical work is based on teamwork. When outcomes are embedded in interpersonal team interaction it becomes much 
more difficult to single out and appraise the contribution of an individual medical professional.

\section{Complexity number 2: shifting goalposts}

Not only is the doctor of 50 years ago unlike the current doctor, society and healthcare have also significantly changed. Medical technical affordances have brought their own societal and ethical dilemmas; rising costs, increasing chronicity of disease and multi-morbidity. The dilemma now arises of whether everything that can be technically done in medicine should be undertaken; end-of-life decisions, et cetera. These all constitute 'wicked problems', i.e. problems that are difficult or impossible to solve because of incomplete, contradictory, and changing requirements that are often difficult to recognise. Future graduates must be increasingly able to deal with these. Generally, wicked problems cannot be solved using algorithms or guidelines. They require the optimal adaptability of the doctor to the given situation.

This leads to a fundamental shift in thinking about the purpose of education. Several decades ago, education was focused mainly on teaching doctors what they needed to know and be able to do. Thus, education disincentivised 'not knowing' and 'uncertainty'. Nowadays, in the evermore complex healthcare environment, the understanding of one's limitations, learning to accept and embrace uncertainty and feeling comfortable in 'not knowing' are playing a more significant role in the educational process. In modern curricula, educating for complexity and uncertainty must be balanced with educating for straightforward and more predictable aspects of the medical profession. Our students will have to be both comfortable in 'knowing and certainty' and 'not knowing and uncertainty'.

\section{Complexity number 3: lifelong learning}

Medical education 50 years ago aimed for a different end point. Then the implicit notion was that four to six years of study would equip medical students with all the skills, knowledge and problem-solving ability needed to last them for the rest of their career, bar some updating and continuous medical education (CME). Nowadays, with the ongoing developments in society and healthcare, graduates will need to continue to learn, or even purposively reinvent themselves as healthcare professionals. Attending workshops and conferences is no longer enough. They must be able to evaluate their strengths and weaknesses and organise their own learning activities. The focus of education is changing dramatically.

One key principle for medical schools remains unchanged. Control over students' learning can only be exercised during the course. Yet responsibility to society starts with graduation. Under the old assumption that medical schools could equip medical students with all they needed for their career, assessing learning was easy. The student completed the curriculum. Then a final examination was taken to ensure that sufficient knowledge and skills had been attained for the future. Now a days, the notion of a final examination is no longer enough. Programmes of assessment where students are increasingly required to show they will assume self-responsibility and accountability for their own learning and assessment offer a more promising approach to achieving lifelong learning.

Such changes, though, are not easy to accept even when they are successfully implemented. Comparing the effects of a new and fundamentally different assessment programme to an old one remains a highly complex task given the multifaceted and complex concept of the 'good doctor' as an outcome measure. Here again, a targeted programme of research, requiring a variety of studies with replication in different cultural contexts, is needed.

\section{Complexity number 4: agility in ontology and epistemology}

Ontology is the domain within philosophy that explores the nature of reality and truth. Epistemology concerns itself with the question of how we 'can know' that reality or truth i.e. how do we know that a belief is justified, that it has foundation, that we can call it knowledge. There are multiple sub domains; the two most well-known are the 'logical positivist' and the 'constructivist' domains. Simply put, a logical positivist view assumes that the reality exists outside ourselves and can be observed objectively. A typical example would be the concept of gravity; you don't have to observe gravity for it to work. Even when you are unconscious, gravity works on you. Constructivist views assume that reality depends on how we perceive it. A typical example is 'colours'. If we see light as a wave-type phenomenon, it is a continuous decrease of wavelengths from near infrared to near ultraviolet. Light does not fundamentally change in nature in that spectrum. However, we clearly see categories such as 'green', 'yellow', 'red', et cetera. From a constructivist view one would argue that these categories do not exist. We make them. Although there might be heated debates amongst scientists as to which one is better, in medical education both views have to be combined. 
If we want to understand a phenomenon such as 'good communication' from a logical positivist perspective we could only examine moving air but from a constructivist point of view we can study perception, meaning making, framing, memory, et cetera. Yet, the extent to which content of the communication is true can be studied through logical positivist perspectives. A typical example of this combination in health is in the vaccination/anti-vaccination debate. From a logical positivist view it is clear that vaccination saves more lives than it costs, but in order to make people adhere and accept that knowledge a constructivist understanding of communication is essential. In medical education, the evidence informing our practice may stem from both perspectives. Most cognitive psychological research fits best with a logical positivist view. Research on collaboration, interdependency, participation, safety, sociocultural learning, et cetera is more aligned with constructivist views.

\section{Complexity number 5: linearity and non-linearity}

Most clinical research assumes rather linear causal relationships. The typical randomised controlled trial tries to examine the linear causal relationship between the drug and the outcome. The trial's design is often optimised on this basis. For example, to 'magnify' the visibility of the linear causal relationship measures are taken to optimise comparability of the study groups. This is defensible because it is plausible to assume that if an effect is found in one context it will most likely generalise to all other contexts. If statins reduce cholesterol in Helsinki, they probably also reduce cholesterol in London, Vancouver or Sydney. This is not the case for many other aspects of healthcare. If a certain communication strategy works with a certain patient in a certain society and culture, this doesn't mean that it will automatically work with a different patient in a different society and culture. The same applies to education. If a certain educational approach works for a certain group of students in a certain society and culture, it doesn't mean that it will automatically work for another group of students in another society and another culture. This is where nonlinearity or complexity of thinking comes in. Research from this perspective seeks to understand why an approach works and what aspects need to be adapted to make it work in a different culture. This is similar to basic sciences in medicine; no two patients are the same. The exact management of a complex illness in one patient may not work for another patient even if they have the same diagnosis. Knowledge of the basic sciences and the pathophysiology behind a diagnosis will enable the doctor to adapt from one patient to another and provide each with optimal quality bespoke care; the 'art of medicine' if you will. The more straightforward the diagnosis is, for instance an Escherichia coli (E. coli) urinary tract infection, the less adaptability is needed. When the patient problem is complex, for instance chronic benign low back pain, more adaptability is needed. Medical education as a concept is highly complex, and hugely impacted by context, society, culture, et cetera. Consequently, medical education research must focus more on understanding the process than on trying to copy or replicate processes.

\section{Complexity number 6: variability of theoretical frameworks and methodologies}

In order to navigate all these other complexities, medical education research must be agile in its use of theoretical frameworks and methodologies. Having multiple theoretical frameworks is often seen as a weakness. We contend it is not. Medicine itself has numerous theoretical frameworks or 'lenses'. Each can explain some aspects of the disease but not all. One of the best examples of a shift in a theoretical framework has occurred with peptic ulcer. Formerly, it was purely seen through a psychosomatic lens; the medical research, diagnostic and therapeutic management focused entirely on understanding, mitigating and treating the impact of stress on acid production (even surgically with high-selective vagotomies). After Barry Marshall's research [1], we now view peptic ulcer treatment mainly through an infectious lens (Helicobacter Pylori). Consequently, diagnostic and therapeutic management have shifted. Complex patient problems require flexibility of theoretical lenses. So do educational problems: behaviourist, constructivist, cognitivist, transformative, human, and social and societal theories are all used in research seeking to understand why certain medical education approaches work. It follows logically that a variety of methodologies must be used. In medical education research various methodologies, both quantitative and qualitative, need to be employed.

For example, Durning et al's research programme focuses on gaining a better understanding of the phenomenon of clinical reasoning. This understanding is necessary to be better able to teach clinical reasoning and to assess it. Many well-intended, but not so well-informed, attempts in the past turned out to be costly mistakes [2]. One of Durning et al's studies employed univariate comparisons and confirmatory factor analytic approaches to unravel the structure of clinical reasoning as a construct. By doing so they studied how scores on various clinical reasoning tasks 
were related and identified the components of clinical reasoning from the patient, the registrar and the supervisor perspectives [3]. In a further study they explored the impact of contextual factors on the process of clinical reasoning using so-called 'think aloud protocol technique.' The quantitative studies sought to understand linear causal relationships between perspectives and the quality of clinical reasoning. The qualitative studies were aimed at understanding how the process of clinical reasoning interacts on a continual basis with its context [4]. Finally, they triangulated their previous results using functional magnetic resonance imaging (fMRI) as an external validation [5].

This risks coming across as jargonistic. Perhaps an analogy with clinical research may help. When we seek to understand how medication impacts on physical parameters, quantitative studies exploring biological availability, first pass effects, elimination or metabolisation pathways are most appropriate. However, to better understand how each patient needs to be informed in a bespoke way, adapting for their prior knowledge, language ability, intellectual capabilities, age, etcetera, then qualitative studies will be more insightful. A one-size-fits-all outcome is neither likely to be found nor practically useful.

\section{Conclusion}

In this short paper, we have tried to justify why medical education research must question whether innovations do lead to better quality doctors and hence improved health care outcomes. Addressing this question though, as we outline, is an extremely complex one.

All medical education research requires rigour. This must always be based on clear, coherent and plausible rationales. These must explain that the chosen methodology is the best to unambiguously address the research question, heed the different ontological and epistemological perspectives and offer a clear decision on whether to approach the issue from a linear or nonlinear angle. Knowing, using and triangulating a vast body of rigorous research approaches, frameworks and technologies is essential if we are to justify the impact of medical education on producing high quality doctors for current and future health care.

\section{Disclosure statement}

No potential conflict of interest was reported by the authors.

\section{ORCID}

Lambert Schuwirth (D) http://orcid.org/0000-0002-6279-5158 Cees van der Vleuten (iD http://orcid.org/0000-0001-68023119

\section{References}

[1] Marshall B. Helicobacter pylori: 20 years on. Clin Med. 2002;2(2):147-152.

[2] Swanson DB, Norcini JJ, Grosso LJ. Assessment of clinical competence: written and computer-based simulations. Assess Eval Higher Educ. 1987;12 (3):220-246.

[3] Durning SJ, Artino A, Boulet J, et al. Making use of contrasting participant views of the same encounter. Med Educ. 2010;44(10):953-961.

[4] Durning SJ, Artino AR Jr, Pangaro L, et al. Context and clinical reasoning: understanding the perspective of the expert's voice. Med Educ. 2011;45(9):927-938.

[5] Durning SJ, Graner J, Artino AR, et al. Using functional neuroimaging combined with a think-aloud protocol to explore clinical reasoning expertise in internal medicine. Mil Med. 2012;177(s1):72-78. 